\title{
Tecer de uma discursividade: o desenvolvimento sustentável na prática do discurso jornalístico ${ }^{1}$
}

\author{
Andressa Batista Farias ${ }^{1}$ e Neusa Inês Philippsen ${ }^{2}$ \\ 1 Graduada em Licenciatura Plena em Letras pela Universidade do Estado de Mato Grosso (UNEMAT), Campus Universitário de \\ Sinop, Brasil. E-mail: andressafariasabf@gmail.com \\ 2 Doutora em Letras pela Universidade de São Paulo (USP). Professora de Língua Portuguesa e Linguística da Universidade do Esta- \\ do de Mato Grosso (UNEMAT), Campus Universitário de Sinop, Brasil. E-mail: neusa@unemat-net.br
}

RESUMO: O objetivo da pesquisa é compreender a discursividade posta na região norte mato-grossense, inserida na Amazônia Legal, na formulação "desenvolvimento sustentável", por meio dos pressupostos teóricos da Análise de Discurso de linha francesa. Neste recorte, analisam-se duas notícias veiculadas na mídia online de Sinop-MT, com o intuito de averiguar, no discurso jornalístico, como a temática "desenvolvimento sustentável" é apresentada nas marcas linguísticas pelo enunciador-jornalista. Busca-se apreender os diferentes efeitos de sentido que aparecem nos diálogos no momento da produção e da circulação dos fatos trazidos pelos textos informativos que circulam nesse espaço discursivo. Dentre os resultados analíticos que se evidenciaram nas formulações, destacam-se embates entre os discursos ambientalistas e desenvolvimentistas, confrontados por manifestações ideológicas e socioeconômicas que são empreendidas, fundamentalmente, pelos sistemas políticos vigentes.

Palavras-chave: Análise de Discurso. Discurso relatado. Mídia online. Norte de Mato Grosso.

\section{Weaving of a discourse: sustainable development in the practice of jour- nalistic discourse}

ABSTRACT: The goal of this research is to understand the discursivity being in the 'sustainable development' formulation in the Northern of Mato Grosso region inserted in Legal Amazon The theoretical postulations used is the French line Discourse Analyses. In this article, we analyze two pieces of News published in the online media in Sinop, aiming to verify how the 'sustainable development' theme is presented according to linguistic enunciations by the journalistic proposer in the journalistic discourse. We search to understand the different meaning effects that are found in the dialogues. Among the analyzed results that were evidenced in the formulations, we can highlight polemics between the environmentalistis' and developmentalists' discourses, confronted in ideological socio-economical opposition that happens fundamentally because of the current political systems.

\footnotetext{
${ }^{1}$ Este artigo representa um recorte das atividades desenvolvidas no Projeto de Pesquisa e Extensão 'Tecer de uma discursividade na região norte mato-grossense da Amazônia Legal: contextos e possibilidades de desenvolvimento frente à sustentabilidade'. 
Keywords: Discourse Analysis. Reported speech. Online media. Northern of Mato Grosso State.

\section{INTRODUÇÃO}

Neste artigo buscamos analisar o discurso jornalístico na formulação desenvolvimento sustentável, por meio dos pressupostos teóricos da Análise de Discurso de linha francesa. Nosso objetivo de estudo visa compreender a discursividade posta na região norte mato-grossense, inserida na tituição de um espaço de dizer em suas relações político-jurídico-ambientais e econômicas que possibilite apreender os efeitos de sentidos que circulam nesta região.

Para este recorte, selecionamos duas notícias, para buscar compreender o papel da mídia online na mobilização de sentidos, e nas quais buscamos identificar as formas de constituição e os posicionamentos do enunciador-jornalista por meio das marcas linguísticas autorizadas por ele na enunciação.

\section{CORPUS DE ANÁLISE}

De acordo com Philippsen (2007), é importante ressaltar que os investimentos na mídia são muito recentes no norte de Mato Grosso. Mais especificamente em Sinop $\stackrel{2}{\text {, }}$ cidade polo dessa região, o primeiro folhetim, impresso, denominado $O$ Sinopeano, surgiu em 1980 com o propósito de enaltecer as terras do norte do Estado de Mato Grosso. Já o primeiro jornal, Gazeta Regional, com formato tabloide, nasceu em 1984,

\footnotetext{
${ }^{2}$ Fundada em 14 de setembro de 1974, Sinop (Sociedade Imobiliária do Noroeste do Paraná), nome dado em homenagem à colonizadora privada, que projetou a cidade, dista $503 \mathrm{~km}$ de Cuiabá, a capital do estado de Mato Grosso.
} Amazônia Legal, e, assim, evidenciar a cons-

como prestador de serviço informativo à Prefeitura Municipal de Sinop.

O jornal escolhido para a seletiva de notícias que compõem o corpus de análise foi o veículo informativo de mídia online sinopense com grande número de acessos: Nortão Notícias ${ }^{3}$. Este jornal publica opiniões, debates, vídeos notícias, eventos e, fundamentalmente, uma grande gama de noticiários das mais diversas áreas, não só da cidade de Sinop, mas de toda a região norte mato-grossense. Dentre eles, destacam-se distintas editorias, tais como a Economia, Política, Educação, Saúde, Polícia, Esporte, Meio Ambiente e Notícias Gerais. Dessa forma, é um suporte midiático de grande representatividade para o contexto comunicacional e informativo do Estado de Mato Grosso.

Dentre os dispositivos teóricos e autores utilizados nas tessituras de análise do discurso, destacamos: Pêcheux (1997), Orlandi (1999), Maingueneau (2004), dentre outros. $\mathrm{E}$, como pressupostos relacionados à imprensa e às possibilidades de gestos de leituras, mais especificamente em notícias jornalísticas, trabalhamos com Sant'Anna (2004), Pinto (2002), Mariani (1998) e outros.

A reflexão analítica, que apresentamos a seguir, pretende verificar as evidências enunciativo-discursivas dos mecanismos e processos discursivos que estabilizam uma notícia e, consequentemente, revelam as tensões entre informar e opinar. Conforme especificado, a trajetória de seleção do cor-

\footnotetext{
${ }^{3}$ Recebe cerca de dois milhões e trezentos mil acessos ao
mês, o que equivale a aproximadamente setenta ou

Recebe cerca de dois milhões e trezentos mil acessos ao
mês, o que equivale a aproximadamente setenta ou oitenta mil acessos diários.
} 
pus iniciou-se com a coletânea de textos que abordavam o assunto "desenvolvimento sustentável"; a escolha final dos textos para a análise ocorreu após a verificação detalhada dos microassuntos que circulavam nos corpora veiculados de 02/2014 a 05/2014, ou seja, nas trinta e uma (31) notícias catalogadas. Selecionamos, então, para este recorte de análise, duas destas notícias do jornal Nortão Notícias.

\section{A ANÁLISE: SENTIDOS SOBRE A FORMU- LAÇÃO “DESENVOLVIMENTO SUSTENTÁ- VEL"}

Para iniciarmos esta análise, salientamos que o enfoque analítico na materialidade discursiva selecionada, ou seja, nos dois textos jornalísticos, ateve-se ao discurso relatado, isto é, na delimitação da noção operatória do discurso relatado que, segundo Sant'Anna (2004, p.127), é o "constituinte maior do texto jornalístico de proposta informativa, é marca constitutiva, sem a qual não se pode imaginar a existência de um certo gênero notícia".

Com as notícias "Governos assinam pacto para reduzir desmatamento na Amazônia Legal após aumento de 28\%" e "Brasil se destaca como o maior produtor de soja do mundo, diz USDA", buscamos compreender os diferentes efeitos de sentido que aparecem nos diálogos entre as muitas vozes que são suscitadas no momento da produção e da circulação dos fatos trazidos pelos textos informativos que circulam nesse espaço discursivo. Destacamos, ainda, que a opção pelo discurso relatado deve-se à praticidade que este recurso operatório tem em identificar as formas de constituição e posicionamentos do enunciador-jornalista por meio das marcas linguísticas autorizadas por ele na enunciação, visto que

o traço tênue entre a confiança e a desconfiança naquilo que a imprensa escrita divulga, neutraliza-se quando o enunciador emprega, com sucesso, o discurso relatado como parte de suas estratégias para se fazer respeitar pela sociedade. 0 discurso que instaura uma verdade submete as opiniões, faz-nos desconfiar que talvez estivéssemos errados em nosso ponto de vista quando ele não coincide com o exposto por aquela voz autorizada e verdadeira. (SANT'ANNA, 2004, p.159).

Por sua vez, as marcas linguísticas tanto podem atribuir claramente o citado a alguém, quando há, por exemplo, o emprego dos discursos direto ${ }^{4}$, indireto ${ }^{5}$ e segundo 6 , quanto podem valer-se de estratégias mais peculiares na utilização do dito do Outro $\stackrel{7}{ }$, como pelo intertexto $\stackrel{8}{ }$, recuperando a apresentação de números, estatísticas, conteúdos de leis, projetos e acordos, e pelo

\footnotetext{
4 "na verificação de recursos tipográficos, tais como dois pontos, aspas, itálico, verbo dicendi; marcas que atribuem o citado integralmente ao outro" (SANT'ANNA, 2004, p. 175).

5 "em verbos dicendi + que (se, como), capazes de recuperar o ato citado do outro no enunciado do jornalista" (SANT'ANNA, 2004, p. 177).

6 "nos modalizadores do tipo 'segundo a, por outro lado' que correspondem a verbos de opinião, tais como: 'imagina que, pretende que, afirma que'" (SANT'ANNA, 2004, p. 177).

${ }^{7}$ Adotamos, em nosso contexto de pesquisa, a noção de Outro em consonância com Maingueneau (2004), que o conceitua sob a forma de "simulacro" que se constrói dele, ou seja, em um processo de tradução nas categorias do mesmo.

8 "Esse recurso pode estar apresentado como parte de um conjunto de informações dadas pelo enunciadorjornalista, não the sendo atribuído nenhum verbo de ação ou, ao contrário, cabendo-lhe uma ação que desencadeia reações" (SANT' ANNA, 2004, p. 179).
} 
discurso narrativizado, recurso este utilizado pelo enunciador-jornalista para apagar 0 dizer do Outro com o propósito de confundir o co-enunciador-leitor com a ideia de informar objetivamente (SANT'ANNA, 2004).

Entender as razões pelas quais o enunciador-jornalista traz vozes de outrem marcadas no texto ou as neutraliza nas formas de apagamento/silenciamento da citação é importante para revelar os sentidos que são mobilizados no cerne dos discursos sobre o desenvolvimento sustentável circundantes na região norte mato-grossense.

Observamos, também, que o discurso relatado utilizado na mídia tem ainda outro efeito que importa ao jornalista: "quando o enunciador cita no discurso direto a fala de alguém, não se coloca como responsável por essa fala, nem como sendo o ponto de referência de sua ancoragem na situação de enunciação" (MAINGUENEAU, 2004, p. 138), ou seja, sabe-se que o enunciadorjornalista é o responsável pela enunciação, no entanto, ele atribui ao Outro a responsabilidade do dito, num eterno jogo de vozes que aparecem simultaneamente em uma dada notícia. É o que veremos, a seguir, nas considerações analíticas apreendidas nos fios discursivos das formulações destacadas em cada notícia.

Para um melhor acompanhamento metodológico, apresentaremos os fragmentos da fala de outrem, que representam a materialidade linguística dos textos do corpus composto pelas duas notícias para, em seguida, tecermos novas reflexões. A ênfase na voz do Outro será destacada em negrito, sendo, portanto, os grifos de nossa autoria.

Apontaremos, também, os seguintes indicadores de incidência do discurso relatado: os fragmentos de texto, nos quais o jor- nalista utiliza essa noção operatória, e a voz de outrem, ou seja, a quem o produtor da notícia recorre para dar autenticidade e veracidade ao seu texto. As formas de discurso relatado visualizadas nos fragmentos serão disponibilizadas de acordo com a seguinte sequência - (1) discurso direto, (2) discurso indireto, (3) discurso segundo, (4) intertexto e (5) discurso narrativizado, identificado por marcas tipográficas, tais como pelo recurso do verbo discendi(v.), indicador da ação, podendo haver exceções quando não é atribuída nenhuma ação ao verbo, mas é apresentado desencadeando reações (d.r.).

\section{Jornal NORTÃO NOTÍCIAS - 1a Notícia}

Editoria: Meio Ambiente Fonte/Autor: Agro Olhar/Vinícius Tavares

Data: 03/02/2014

APRESENTAÇÃO 01: TíTULO: "Governos assinam pacto para reduzir desmatamento na Amazônia Legal após aumento de $28 \%{ }^{9}$ "

\section{Fragmentos (F) da Notícia 1 (N1)}

N1F1 - O governo federal e os nove estados da Amazônia Legal (Acre, Amapá, Amazonas, Maranhão, Mato Grosso, Pará, Rondônia, Roraima e Tocantins) assinaram um acordo para combater o desmatamento ilegal na região.

- Voz do Outro: Governo federal;

- Formas de Discurso Relatado: Discurso narrativizado, v. assinar

9 Disponível em: <http://www.nortaonoticias.com.br/ ambiente/96735/Governos_assinam_pacto_para_redu zir_desmatamento_na_Amazonia_Legal_apos_aument o_de_28_>. Acesso em: 18 mar. 2014. 
N1F2 - O acordo de cooperação firmado entre o Instituto Brasileiro do Meio Ambiente e dos Recursos Naturais (Ibama) e as autoridades locais vai permitir a gestão florestal do bioma.

- Voz do Outro: Acordo de cooperação, Instituto Brasileiro do Meio Ambiente e dos Recursos Naturais (Ibama) e as autoridades locais;

- Formas de Discurso Relatado: Intertexto, v. firmar; Discurso narrativizado, v. vai permitir (d.r.).

N1F3 - O acordo é assinado após divulgação de que o desmatamento na Amazônia voltou a crescer e subiu $\mathbf{2 8} \%$, segundo números do Projeto de Monitoramento da Floresta Amazônica por Satélites (Prodes), do Instituto Nacional de Pesquisas Espaciais (Inpe).

- Voz do Outro: Acordo, 28\%, segundo números do Projeto de Monitoramento da Floresta Amazônica por Satélites (Prodes), do Instituto Nacional de Pesquisas Espaciais (Inpe).

- Formas de Discurso Relatado: Intertexto, (d.r.), Discurso segundo, EO, Modalizador: segundo ${ }^{10}$.

N1F4 - Pelo termo assinado, a parceria valerá pelos próximos três anos e atuará, entre outras ações, no aperfeiçoamento dos documentos de origem da madeira e no rastreamento dos veículos que fazem o

10 O discurso segundo, tal como apresentado por Sant'Anna (2004, p. 177), é um recurso utilizado para identificar a personalização da "experiência de um indivíduo", dessa forma, é comum visualizar a expressão de opinião (EO) por meio da modalização em discurso segundo, que se localiza entre o discurso direto e o indireto. transporte do material em território amazônico.

- Voz do Outro: Termo assinado, três anos;

- Formas de Discurso Relatado: Intertexto, v. valer/atuar/rastrear.

N1F5 - Segundo informações do Ministério do Meio Ambiente (MMA) o país já cumpriu $\mathbf{7 6 \%}$ da meta voluntária de redução do desflorestamento prevista para 2020.

- Voz do Outro: Segundo informações do Ministério do Meio Ambiente (MMA), 76\%;

- Formas de Discurso Relatado: Discurso segundo, EO, Modalizador: segundo, Intertexto, v. cumprir.

N1F6 - Em 2012, por exemplo, houve a menor taxa de desmatamento da região, equivalente a $4.571 \mathbf{~ k m}^{2}$.

- Voz do Outro: Menor taxa, $4.571 \mathrm{~km}^{2}$;

- Formas de Discurso Relatado: Intertexto, (d.r.).

N1F7 - O índice representa queda de $\mathbf{8 4 \%}$ quando comparado a 2004, data de implantação do Plano de Prevenção e Controle do Desmatamento na Amazônia (PPCDAm).

- Voz do Outro: Índice, 84\%, Plano de Prevenção e Controle do Desmatamento na Amazônia (PPCDAm);

- Formas de Discurso Relatado: Intertexto, v. representar.

N1F8 - Entre junho de 2012 e agosto de 2013, no entanto, os dados mostraram aumento de $\mathbf{2 8 \%}$ em relação ao período anterior.

- Voz do Outro: Dados, 28\%; 
- Formas de Discurso Relatado: Intertexto, v. mostrar.

N1F9 - As novas medidas têm por objetivo frear esse aumento.

- Voz do Outro: Novas medidas;

- Formas de Discurso Relatado: Intertexto, (d.r.).

N1F10 - O pacto foi firmado no âmbito do Fórum de Secretários da Amazônia, instituído pela ministra do Meio Ambiente Izabella Teixeira para fomentar o diálogo com os governantes que estão mais próximos da realidade da floresta.

- Voz do Outro: Pacto, ministra do Meio Ambiente Izabella Teixeira;

- Formas de Discurso Relatado: Intertexto, v. firmar, Discurso narrativizado, v. instituir.

N1F11 - Desde novembro, o grupo se reúne em encontros periódicos, em Brasília, para discutir a situação de cada local e implantar ações de melhorias para o bioma.

- Voz do Outro: O grupo;

- Formas de Discurso Relatado: Discurso narrativizado, v. reunir/discutir/implantar.

N1F12 - "Haverá uma mudança nas relações com os estados, diminuindo a verticalização e estabelecendo a horizontalidade. A questão dos documentos de origem florestal e o debate sobre assentamentos rurais devem estar em primeiro lugar", afirmou ao lembrar que $o$ acordo vai promover maior integração entre os governos locais e a esfera federal.

- Voz do Outro: Ministra do Meio Ambiente Izabella Teixeira, o acordo;
- Formas de Discurso Relatado: Discurso direto, v (s). afirmar/lembrar, Intertexto, v. promover.

N1F13 - "A intenção é valorizar o espaço político do Fórum e estabelecer um diálogo permanente para que todos possam trabaIhar juntos", destacou.

- Voz do Outro: Ministra do Meio Ambiente Izabella Teixeira;

- Formas de Discurso Relatado: Discurso direto, v. destacar.

\section{Jornal NORTÃO NOTÍCIAS - 2a Notícia}

Editoria: Economia Fonte/Autor: Agro debate/Vívian Lessa

Data: 12/02/2014

APRESENTAÇÃO 02: TíTULO: "Brasil se destaca como o maior produtor de soja do mundo, diz USDA $\underline{11 "}$

\section{Fragmentos (F) da Notícia 2 (N2)}

N2F1 - Brasil é o maior produtor de soja do mundo, pelo menos é o que aponta o último relatório do Departamento de Agricultura dos Estados Unidos (USDA), divulgado nesta segunda-feira (10).

- Voz do Outro: Relatório,

- Formas de Discurso Relatado: Intertexto, v. apontar

N2F2 - O levantamento mostra que o país cresceu em quase $10 \%$ a produção de oleaginosa na última temporada, passando de

11 Disponível em: <http://www.nortaonoticias.com.br/ economia/99144/Brasil_se_destaca_como_o_maior_ produtor_de_soja_do_mundo_diz_USDA $>$. Acesso em: 20 mar. 2014.

https://periodicos.unifap.br/index.php/estacao Macapá, v. 6, n. 1, p. 105-116, jan./abr. 2016 
82 milhões de toneladas para $\mathbf{9 0}$ milhões de toneladas.

- Voz do Outro: O levantamento, $10 \%, 82$ milhões, 90 milhões;

- Formas de Discurso Relatado: Intertexto, v. mostrar/passar.

N2F3 - Com a expansão, o Brasil passou na frente da safra dos Estados Unidos, cuja produção será de $\mathbf{8 9 , 5}$ milhões de toneladas na campanha atual.

- Voz do Outro: 89,5 milhões;

- Formas de Discurso Relatado: Intertexto, (d.r.).

N2F4 - Neste cenário, destaca-se Mato Grosso representando $\mathbf{2 9 \%}$ da produção nacional.

- Voz do Outro: 29\%,

- Formas de Discurso Relatado: Intertexto, v. representar.

N2F5 - O estado deve colher 26,2 milhões de toneladas do grão na safra $13 / 14$, conforme dados da Companhia Nacional de Abastecimento (Conab).

- Voz do Outro: 26,2 milhões, conforme dados da Companhia Nacional de Abastecimento (Conab);

- Formas de Discurso Relatado: Intertexto, v. colher, Discurso segundo, EO, Modalizador: conforme.

N2F6 - Em visita a região de Lucas do Rio Verde (MT) nesta terça-feira (11), a presidente Dilma Rousseff enfatizou o potencial produtivo mato-grossense.

- Voz do Outro: A presidente Dilma Rousseff;

- Formas de Discurso Relatado: Discurso narrativizado, v. enfatizar.
N2F7 - Conforme ela, Mato Grosso é um dos principais responsáveis pelo recorde na produção de grãos do Brasil, que deverá ser de 193 milhões de toneladas.

- Voz do Outro: Conforme ela, 193 miIhões;

- Formas de Discurso Relatado: Discurso segundo, EO, Modalizador: conforme, Intertexto, v. dever.

N2F8 - A presidente também ressaltou a necessidade da construção de locais para armazenamento dos grãos.

- Voz do Outro: A presidente;

- Formas de Discurso Relatado: Discurso narrativizado, v. ressaltar.

N2F9 - Rousseff defendeu o plano de armazenagem lançado em 2013 pelo governo federal, que prevê a concessão de $\mathbf{R} \mathbf{5}$ biIhões em empréstimos por ano para melhorar a capacidade de estocagem do país.

- Voz do Outro: Rousseff, R\$ 5 bilhões;

- Formas de Discurso Relatado: Discurso narrativizado, v. defender, Intertexto, v. prever.

N2F10 - "Mudaremos a face do agronegócio quanto mais tivermos armazenagem eficiente".

- Voz do Outro: Rousseff;

- Formas de Discurso Relatado: Discurso direto (d.r.).

N2F11 - Mesmo assim, admitiu que o setor enfrenta alguns gargalos, como as questões de logística e armazenagem.

- Voz do Outro: A Presidente;

- Formas de Discurso Relatado: Discurso indireto, v. admitir. 
N2F12 - "Precisamos romper com as limitações e os gargalos de infraestrutura do Brasil - e a armazenagem é um gargalo".

- Voz do Outro: A Presidente;

- Formas de Discurso Relatado: Discurso direto (d.r.).

N2F13 - Para isso, o governo se comprometeu a integrar os modais de transporte em Mato Grosso.

- Voz o Outro: O governo;

- Formas de Discurso Relatado: Discurso narrativizado, v. comprometer.

N2F14 - "Nós vamos explorar o modal ferroviário e o hidroviário, que o Brasil sempre abandonou, e o rodoviário, que o Brasil permitiu que ficasse sucateado", disse.

- Voz do Outro: A Presidente Dilma Rousseff;

- Formas de Discurso Relatado: Discurso direto, v. dizer.

A partir da leitura atenta das duas apresentações de fragmentos textuais dispostos acima, ressaltamos as recorrências empregadas pelos enunciadores-jornalistas e os possíveis efeitos de sentido que essas estratégias tendem a evocar no imaginário do sujeito-leitor. Dessa forma, conforme Pechêux,

o sentido de uma palavra, de uma expressão, de uma proposição, etc., não existe 'em si mesmo' (isto é, em sua relação transparente com a literalidade do significante), mas, ao contrário, é determinado pelas posições ideológicas que estão em jogo no processo sócio-histórico em que as palavras, expressões e proposições são produzidas (isto é, reproduzidas) (PECHÊUX, 1997, p. 160).
Assim, se concordarmos com a tese acima, coadunaremos com a ideia de que as palavras, expressões, proposições etc., mudam de sentido segundo as posições sustentadas por aqueles que as empregam, o que quer dizer que elas adquirem seu sentido em referência a essas posições, isto é, em referência às formações ideológicas nas quais essas posições se inscrevem.

Do mesmo modo, ao refletirmos sobre a constituição dos sentidos e dos sujeitos, "considerando a produção de sentidos enquanto parte de suas vidas, seja enquanto sujeitos, seja enquanto membros de uma determinada forma de sociedade" (ORLANDI, 1999, p. 15), podemos, então, atribuir aos jornalistas um papel de destaque na construção de efeitos de sentido no espaço enunciativo-discursivo de circulação das notícias, que se localiza, essencialmente, na circunvizinhança do norte de Mato Grosso.

Os recursos empregados para tentar tornar as informações verossímeis, imparciais e objetivas tendem a dar credibilidade ao enunciador-jornalista e mesmo à instituição. Isto porque,

cria-se uma tensão entre dois pólos constitutivos da natureza do que se prescreve como o papel da imprensa escrita: por um lado, deve estar fora, isto é, transpor o fato social para o espaço discursivo do jornal, mantendo a objetividade; por outro, deve estar dentro, isto é, ser espaço discursivo que reenvia sentidos ao espaço social, abrindo-se a posicionamentos ideológicos, já que ela mesma é integrante da sociedade na qual ocorrem os fatos sociais. (SANT'ANNA, 2004, p. 98-99).

Entre os recursos utilizados, o destaque evidenciado em nossas análises está na 
preocupação em acentuar as formas de discurso relatado impresso por vozes legitimadas e autorizadas para que os textos, de base informativa, tenham caráter de verdade e apresentem o modelo ideal de jornalismo, aquele que delimita as informações objetivas, sem expressão de opinião.

O jornalista, dessa forma, imbuído da ideologia institucional e da necessidade em utilizar uma competência discursiva para se revelar conhecedor de uma linguagem hermética, requerida pelo campo discursivo a que este se propõe, acredita que, garantindo a fonte como efeito da restituição exata das palavras de outrem, traz nestas marcas lugares legítimos do seu posicionamento (SANT'ANNA, 2004).

No entremeio das marcas de autoridade e dos dados estatísticos, contudo, revela-se um enunciador-jornalista que pincela mesclas de opinião e, nas escolhas sintáticas, permeia sutilezas que refletem o encaminhamento semântico do processo discursivo. Dessa maneira, o discurso narrativizado 12 , que revela as posições enunciativas das quais se valem os enunciadores-jornalistas nos dois textos analisados, aparece 08 (oito) vezes nos recortes do corpus selecionado (em N1F1, N1F2, N1F10, N1F11, N2F6, N2F8, N2F9, N2F12).

Os usos preferenciais desse tipo de citação no corpo enunciativo-discursivo das notícias são exemplos característicos da transformação do dizer do Outro, da identificação com o discurso do Outro ou ainda

12 Conforme Sant'Anna (2004), o discurso narrativizado (forma narrativizada máxima de um possível discurso indireto) é uma forma mais apagada da atribuição do discurso a outro e em que o enunciador-jornalista capta, modifica ou até mesmo apaga o dizer do Outro, com o intuito de confundir-se com a ideia de informar objetivamente. do completo apagamento deste Outro. Essa atenuação da presença do Outro é que imprime os efeitos de sentido do informar objetivamente, como também sobre as origens dos dados informados. A estratégia do uso do discurso narrativizado, dessa forma, pode ser considerada como uma mescla de apagamento da voz autorizada, que se confunde com a impessoalidade do discurso do jornalista, isto porque, conforme Sant' Anna (2004, p.285), "ao não ser apresentada como se constituindo em espaço qualificado para a opinião, a notícia não cria no receptor potencial as estratégias para captar possíveis opiniões inerentes a qualquer manifestação da subjetividade humana".

Se no discurso narrativizado a fonte do relato é atenuada e a construção do simulacro do Outro se confunde no discurso do enunciador-jornalista, é possível, então, constatar nessa constituição da dinâmica discursiva que há uma constante tensão entre informar objetivamente e opinar. Isso decorre, fundamentalmente, porque,

O sujeito enunciador produz um efeito de distanciamento - o jornalista projeta a imagem de um observador imparcial - e marca uma diferença com relação ao que é falado, podendo, desta forma, formular juízos de valor, emitir opiniões etc., justamente porque não se 'envolveu' com a questão. (MARIANI, 1998, p.60).

Tal estratégia, porém, geralmente passa despercebida pelo leitor porque os redatores, ao mesmo tempo, se valem de recursos de vozes autorizadas (oficiais), como exemplo, aparecem nas notícias às vozes da Ministra do Meio Ambiente, Izabella Teixeira, e da Presidente Dilma Rousseff. O discurso direto aparece no corpus cinco vezes: (no 
N1F12, N1F13, N2F10, N2F12, N2F14).

Uma das justificativas para a preferência do discurso direto pode estar relacionada com o que Pinto chama de "efeito de objetividade narrativa" para o qual, estrategicamente, "o enunciador se apaga deixando 'os fatos falarem por si mesmos'" (PINTO, 2002, p. 93). Dessa maneira, o jornalista apenas se responsabilizaria em transmitir as informações recebidas de outras fontes, com isenção de avaliação, objetividade e transparência para um leitor que desconhece os acontecimentos e quer tomar conhecimento dos fatos.

Portanto, para mostrar a preocupação com a verdade e estimular os efeitos de objetividade, os enunciadores-jornalistas, responsáveis pelas produções textuais das notícias apresentadas acima, valem-se de vozes de autoridades para reiterar e validar as informações fornecidas, que revelam efeitos de sentido que intuem transmitir a realidade objetiva dos eventos narrados.

As marcas discursivo-linguísticas verificadas e transcritas da materialidade, juntamente com as estratégias do intertexto, que retratam as certezas técnicas, do campo da legalidade, dos dados estatísticos com números, acordos e projetos de lei, pretendem não só reconstituir os fatos apresentados em uma dada notícia, mas também mostrar que as citações de autoridade reforçam a verdade e legitimidade das informações apresentadas. Esse esforço pela impessoalidade no jornalismo não é recente, e, segundo Mariani, o jornalismo passa a adotar o discurso relatado,

Sobretudo a partir das décadas de 40/50, época em que as matérias assinadas e não-assinadas começam cada vez mais a utilizar uma 'gramática da impessoalida- de', [...] na tentativa de levar a uma demarcação das fronteiras entre ditos diferentes e, deste modo, produzindo um apagamento do locutor-jornalista, reforçar a idéia de que tanto os fatos quanto os sujeitos falam por si. As falas autonomamente reproduzidas sinalizariam, deste ponto de vista, as origens do dizer ou fontes de sentidos sobre os quais o jornal não tem controle ou responsabilidade. (MARIANI, 1998, p.189).

Assim, como vimos, a impossibilidade de objetividade jornalística se mostra evidente quando os textos passam a ser analisados no todo do tecido discursivo. De acordo com as marcas discursivas reveladas nas análises, podemos afirmar que a proposta político-econômica dominante na região e no Estado de Mato Grosso associa-se ao projeto de desenvolvimento, conforme se pode observar na Apresentação 02, mais especificamente nos fragmentos (N2F7 e N2F10), na voz da autoridade máxima brasileira, a presidente Dilma Roussef, ao dizer que "Mato Grosso é um dos principais responsáveis pelo recorde na produção de grãos do Brasil, que deverá ser de 193 miIhões de toneladas" e que "Mudaremos a face do agronegócio quanto mais tivermos armazenagem eficiente".

Nas nuanças do discurso narrativizado, verifica-se, também, o imperativo do desenvolvimento, como na formulação seis da notícia dois (N2F6) ${ }^{13}$, em que se evidencia na materialidade discursiva o substantivo "potencial" e o adjetivo "produtivo", pois, "Em visita a região de Lucas do Rio Ver-

${ }^{13}$ Os fragmentos (N2F6, N2F7 e N2F10) encontram-se disponíveis em: <http://www.nortaonoticias.com.br/ economia/99144/Brasil_se_destaca_como_o_maior_ produtor_de_soja_do_mundo_diz_USDA $>$. Acesso em: 20 mar. 2014. 
de (MT) nesta terça-feira (11), a presidente Dilma Rousseff enfatizou o potencial produtivo mato-grossense", numa demonstração de que a preservação ambiental e a sustentabilidade estão à mercê do embate promovido pelo setor de produção.

Por outro lado, há a circulação de sentidos de entidades que procuram disseminar o discurso ambientalista, demonstrando preocupação com os altos índices de desmatamento que a região norte do Estado de Mato Grosso vem atingindo nos últimos anos. É o caso do Instituto Brasileiro do Meio Ambiente e dos Recursos Naturais (Ibama), do Fórum de Secretários da Amazônia, instituído pela Ministra do Meio Ambiente Izabella Teixeira e de autoridades locais, visto que, conforme se evidencia na primeira notícia, um "acordo é assinado após divulgação de que o desmatamento na Amazônia voltou a crescer e subiu $28 \%$, segundo números do Projeto de Monitoramento da Floresta Amazônica por Satélites (Prodes), do Instituto Nacional de Pesquisa Espaciais (Inpe)" ${ }^{14}$ (N1F3).

Tais sentidos já se apresentam na entrada semântica do título da primeira notícia "Governos assinam pacto para reduzir desmatamento na Amazônia Legal após aumento de $28 \% "$, que oferece ao leitor efeitos de sentido sobre a sustentabilidade na região, e que reforça a assertiva de Rossi (2000, p.44), quando diz que "o título é necessariamente a primeira coisa que o leitor vai ter acesso no seu processo de leitura,

\footnotetext{
${ }^{14}$ TAVARES, V. Agro Olhar. Governos assinam pacto para reduzir desmatamento na Amazônia Legal após aumento de 28\%. 03/02/2014. Disponível em: <http://www.nortaonoticias.com.br/ambiente/96735/ Governos_assinam_pacto_para_reduzir_desmatamen to_na_Amazonia_Legal_apos_aumento_de_28_>. Acesso em: 18 mar. 2014.
}

sua importância é fundamental".

O ápice do discurso ambientalista, contudo, se faz presente na forma de discurso direto manifestado pela Ministra do Meio Ambiente, Izabella Teixeira, quando afirma que "haverá uma mudança nas relações com os estados, diminuindo a verticalização e estabelecendo a horizontalidade. A questão dos documentos de origem florestal e o debate sobre assentamentos rurais devem estar em primeiro lugar" $\stackrel{15}{ }$.

\section{CONCLUSÃO}

Ao verificarmos as marcas linguísticodiscursivas dos fios discursivos que tecem nosso corpus, é possível afirmar que há duas grandes vozes recorrentes, inscritas em formações discursivas distintas: o discurso desenvolvimentista e o discurso que se apresenta como ecologicamente correto. No decorrer de nossas análises, os discursos, quando confrontados nas formas de discurso relatado, tenderam a mostrar efeitos de sentido de um discurso que se põe em evidência: o desenvolvimentista.

É, portanto, no embate entre as formações discursivas desenvolvimentista e sustentável que a temática desenvolvimento sustentável se manifesta e mobiliza distintos sentidos veiculados pela mídia online nos entornos da região norte matogrossense. O discurso jornalístico, dessa forma, é determinado pelas posições ideológicas que estão em jogo no processo só-

\footnotetext{
${ }^{15}$ TAVARES, V. Agro Olhar. Governos assinam pacto para reduzir desmatamento na Amazônia Legal após aumento de 28\%. 03/02/2014. Disponível em: <http://www.nortaonoticias.com.br/ambiente/96735/ Governos_assinam_pacto_para_reduzir_desmatamen to_na_Amazonia_Legal_apos_aumento_de_28_>. Acesso em: 18 mar. 2014.
} 
cio-histórico em que as palavras, expressões e proposições são produzidas e o enunciador-jornalista, por sua vez, pincela mesclas de opinião e, nas escolhas sintáticas, permeia sutilezas que refletem o encaminhamento semântico do processo discursivo que circula nos espaços de reprodução dos textos informativos veiculados e que estão em consonância com as manifestações ideológicas e socioeconômicas dos sistemas políticos vigentes.

\section{REFERÊNCIAS}

LESSA, V. Agrodebate. Brasil se destaca como o maior produtor de soja do mundo, diz USDA. 12/02/2014. Disponível em: <http://www.nortaonoticias.com.br/econo mia/99144/Brasil_se_destaca_como_o_ma ior_produtor_de_soja_do_mundo_diz_US

DA>. Acesso em: 20 mar. 2014.

MAINGUENEAU, D. Análise de textos de comunicação. 3. ed. São Paulo: Cortez: 2004.

MARIANI, B. O PCB e a imprensa: os comunistas no imaginário dos jornais (19221989). Rio de Janeiro: Revan; Campinas: Editora da UNICAMP, 1998.

ORLANDI, E. Análise de Discurso: Princípios e Procedimentos. Campinas: Pontes, 1999. PÊCHEUX, M. Semântica e Discurso: uma Crítica à Afirmação do Óbvio. 3. ed. Campinas: Editora da UNICAMP, 1997.

PHILIPPSEN, N. I. Mídia Impressa e Heterogeneidade: polêmicas da esfera da atividade madeireira no espaço discursivo da Amazônia Legal. Dissertação de Mestrado. Cuiabá: Universidade Federal de Mato Grosso, 2007.

PINTO, M. J. Comunicação e discurso: introdução à análise de discursos. 2. ed. São Paulo: Hacker Editores, 2002.
ROSSI, C. O que é jornalismo. São Paulo: Brasiliense, 2000.

SANT'ANNA, V. L. de A. 0 trabalho em notícias sobre o Mercosul: heterogeneidade enunciativa e noção de objetividade. São Paulo: EDUC, 2004.

TAVARES, V. Agro Olhar. Governos assinam pacto para reduzir desmatamento na Amazônia Legal após aumento de $\mathbf{2 8 \%}$. 03/02/2014. Disponível em: <http://www. nortaonoticias.com.br/ambiente/96735/G overnos_assinam_pacto_para_reduzir_des matamento_na_Amazonia_Legal_apos_au mento_de_28_>. Acesso em: 18 mar. 2014.

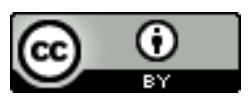

License information: This is an openaccess article distributed under the terms of the Creative Commons Attribution License, which permits unrestricted use, distribution, and reproduction in any medium, provided the original work is properly cited.

Artigo recebido em 22 de agosto de 2015.

Avaliado em 18 de fevereiro de 2016.

Aceito em 09 de março de 2016.

Publicado em 25 de maio de 2016.

\section{Como citar este artigo (ABNT):}

FARIAS, Andressa Batista; PHILIPPSEN, Neusa Inês. Tecer de uma discursividade: o desenvolvimento sustentável na prática do discurso jornalístico. Estação Científica (UNIFAP), Macapá, v. 6, n. 1, p. 105-116, jan./abr. 2016. 